\title{
Digital Accessible Knowledge and well-inventoried sites for birds in Mexico: baseline sites for measuring faunistic change
}

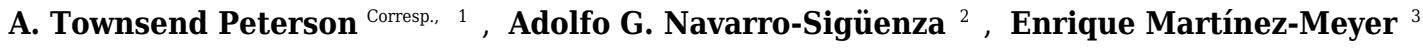 \\ 1 Biodiversity Institute, University of Kansas, Lawrence, Kansas, United States \\ 2 Museo de Zoología, Facultad de Ciencias, Universidad Nacional Autónoma de México, México, Distrito Federal, México \\ 3 Instituto de Biología, Universidad Nacional Autónoma de México, México, Distrito Federal, México \\ Corresponding Author: A. Townsend Peterson \\ Email address: town@ku.edu
}

Background. Faunal change is a basic and fundamental element in ecology, biogeography, and conservation biology, yet vanishingly few detailed studies have documented such changes rigorously over decadal time scales. This study responds to that gap in knowledge, providing a detailed analysis of Digital Accessible Knowledge of the birds of Mexico, designed to marshal DAK to identify sites that were sampled and inventoried rigorously prior to the beginning of major global climate change (1980).

Methods. We accumulated DAK records for Mexican birds from all relevant online biodiversity data portals. After extensive cleaning steps, we calculated completeness indices for each $0.05^{\circ}$ pixel across the country; we also detected 'hotspots' of sampling, and calculated completeness indices for these broader areas as well. Sites were designated as well-sampled if they had completeness indices above $80 \%$ and $>200$ associated DAK records.

Results. We identified 100 individual pixels and 20 broader 'hotspots' of sampling that were demonstrably well-inventoried prior to 1980. These sites are catalogued and documented to promote and enable resurvey efforts that can document events of avifaunal change (and non-change) across the country on decadal time scales.

Conclusions. Development of repeated surveys for many sites across Mexico, and particularly for sites for which historical surveys document their avifaunas prior to major climate change processes, would pay rich rewards in information about distributional dynamics of Mexican birds. 
2 Digital Accessible Knowledge and well-inventoried sites for birds in

3 Mexico: baseline sites for measuring faunistic change

4 A. Townsend Peterson ${ }^{1}$, Adolfo G. Navarro-Sigüenza², and Enrique Martínez-Meyer ${ }^{3}$

$5 \quad{ }^{1}$ Biodiversity Institute, University of Kansas, Lawrence, Kansas 66045 USA

$6 \quad{ }^{2}$ Museo de Zoología, Facultad de Ciencias, Universidad Nacional Autónoma de México, Mexico

7 City 04510, Mexico

$8{ }^{3}$ Instituto de Biología, Universidad Nacional Autónoma de México, Mexico City 04510, Mexico

9 Corresponding author: A. Townsend Peterson, town@ku.edu 
10 Background. Faunal change is a basic and fundamental element in ecology, biogeography, and

11 conservation biology, yet vanishingly few detailed studies have documented such changes

12 rigorously over decadal time scales. This study responds to that gap in knowledge, providing a

13 detailed analysis of Digital Accessible Knowledge of the birds of Mexico, designed to marshal

14 DAK to identify sites that were sampled and inventoried rigorously prior to the beginning of

15 major global climate change (1980).

16 Methods. We accumulated DAK records for Mexican birds from all relevant online biodiversity

17 data portals. After extensive cleaning steps, we calculated completeness indices for each $0.05^{\circ}$

18 pixel across the country; we also detected 'hotspots' of sampling, and calculated completeness

19 indices for these broader areas as well. Sites were designated as well-sampled if they had

20 completeness indices above $80 \%$ and $>200$ associated DAK records.

21 Results. We identified 100 individual pixels and 20 broader 'hotspots' of sampling that were

22 demonstrably well-inventoried prior to 1980. These sites are catalogued and documented to

23 promote and enable resurvey efforts that can document events of avifaunal change (and non-

24 change) across the country on decadal time scales.

25 Conclusions. Development of repeated surveys for many sites across Mexico, and particularly

26 for sites for which historical surveys document their avifaunas prior to major climate change

27 processes, would pay rich rewards in information about distributional dynamics of Mexican

28 birds.

\section{Introduction}


30 The temporal dynamics of geographic distributions of species and composition of local biotic

31 communities are central to much of biogeography, macroecology, and conservation biology

32 (Lavergne et al. 2010). That is, how species' distributions evolve through time and how

community composition changes as a result are key in determining essentially all results in these

areas of ecology and evolutionary biology. Although biogeographers invest fundamentally in

retracing the geography of evolving lineages over long periods of time, strangely little

information exists on short-term dynamics of species’ distributions and community composition

(e.g., Nunes et al. 2007; Tingley \& Beissinger 2009).

An important opportunity to understand these shorter-term dynamics of distributions and communities by means of longitudinal comparisons of inventories of local faunas and floras. That is, when a baseline of solid, complete, and well-documented knowledge exists about a site

(Colwell \& Coddington 1994; Peterson \& Slade 1998; Soberón \& Llorente 1993), re-surveys over years, decades, and centuries can offer a fascinating view into the natural dynamics of species' ranges and the effects of human presence and activities. Drivers of these changes may act both on local scales (e.g., effects of land use change) and on global scales (e.g., effects of climate change), and potentially may interact as well; studies integrating and comparing effects of

46 different such drivers are particularly rare (e.g., Peterson et al. 2015; Rubidge et al. 2011). Of course, detailed documentation of species identifications and of the completeness of inventory efforts are necessary for both the baseline and the resurvey, but the general paradigm has considerable potential.

Previous baseline/re-survey efforts have yielded fascinating information about faunas and

51 floras. For example, Nilsson, Franzén \& Jönsson (2008) documented 40\% extirpation of butterfly species over a 90+ year span on a plot in southern Sweden, and found that species disappearing

53 from the fauna tended to be those with a short flight length period, narrow habitat breadth, and

54 small distributional area in Europe; however, only flight length period was significant in 
55 multivariate analyses. Grixti \& Packer (2006) studied bee communities at a site in southern

56 Ontario, and documented community changes and diversity increases over a $40+$ year span, likely

57 in response to successional changes in the surrounding landscapes. Scholes \& Biggs (2005)

58 proposed a biodiversity intactness index, and showed widespread population declines,

59 particularly among mammals, and ecosystem declines concentrated in grasslands, across a large

60 region of southern Africa. In California, important efforts have been carried out to resurvey sites

61 studied by Joseph Grinnell a century ago, detecting fascinating distributional (Tingley \&

62 Beissinger 2009), phenotypic (Leache, Helmer \& Moritz 2010), and genetic (Rubidge et al. 2011)

63 changes in vertebrate species and communities (Moritz et al. 2008).

64 Within Mexico, such before-and-after studies have been particularly scarce. Peterson \&

65 Navarro-Sigüenza (2005) used nineteenth-century sources to reflect on changes in the avifauna of

66 the Valley of Mexico over the twentieth century. In a particularly interesting example, Olvera-

67 Vital (2012) re-surveyed the avifauna of Misantla, Veracruz — of great interest is that the avifauna

68 has been quite stable over the past 50-100 years, which apparently reflects the very early mass-

69 disturbance to the natural habitats of that region (Sánchez G. 1998), such that the baseline

70 inventory was itself already post-disturbance. On broader and coarser spatial scales, Peterson et

71 al. (2015) assessed countrywide changes in Mexican endemic bird species' distributions between

72 the middle of twentieth century and early twenty-first century, and found dominant effects of

73 changes in temperature (and not of human impact on landscapes or changes in precipitation) in

74 driving avifaunal change. Curiously, however, to our knowledge at least, this short list includes

75 all sites that have seen baseline and re-survey inventories of birds, such that the nature and

76 pattern of avifaunal change across Mexico remains very poorly characterized.

The purpose of this paper is to stimulate and enable a next generation of such re-survey

78 efforts for birds across Mexico by means of cataloguing sites for which solid documentation

79 exists for the original baseline inventory, and for which the baseline inventory is demonstrably 
80 complete. We reviewed all existing Digital Accessible Knowledge (DAK; Sousa-Baena, Garcia \&

81 Peterson 2013) regarding the birds of Mexico: we probed four major online data portals for

82 relevant data (i.e., bird records from Mexico prior to 1980), and evaluated inventory

83 completeness at two spatial extents ( $0.05^{\circ}$ grid squares, and coarser hotspots of sampling). We

84 present a simple list and catalog of sites that have seen relatively complete (i.e., $\geq 80 \%$ of

85 avifauna known and documented) inventories, as a challenge and stimulus to the ornithological

86 community in Mexico. Resurvey of these localities would provide rich and informative rewards

87 in understanding the dynamics of bird populations and distributions across the country.

\section{Materials \& Methods}

89 This analysis is based on a suite of assumptions about data quality and appropriate resolutions

90 inherent in biodiversity data. For instance, we used single days as the unit of sampling effort

91 throughout our analyses, as this resolution has proven an effective balance between too much and

92 too little resolution; temporal information finer than the level of day is rarely available with older

93 biodiversity data, whereas coarse temporal resolution can underappreciate the efficacy of short-

94 term, intensive inventory efforts. Hence, a basic working data set was the combination of species

95 identification, day (i.e., unique combinations of year, month, and day), and place. This latter we

96 defined in various ways, described below, but we note that we used both geographic coordinates

97 and textual locality descriptions to avoid loss of information owing to lack of georeferencing, at

98 least to all extents possible.

99 Data sources and quantities. We downloaded data from four basic sources for this study:

100 the Global Biodiversity Information Facility (GBIF; http://www.gbif.org), VertNet

101 (http://www.vertnet.org/), the Red Mundial de Información de la Biodiversidad (REMIB;

102 http://www.conabio.gob.mx/remib/doctos/remib esp.html), and UNIBIO

103 (http://unibio.unam.mx/). Each of these biodiversity information networks has its respective 
104 strengths and weaknesses, and considerable overlaps exist among them in coverage of

105 biodiversity information sources. We downloaded data on bird occurrences in Mexico from all

106 four, and trusted that duplication would be removed in our data cleaning steps; for this reason, we

107 are unable to develop comparisons among the different data resources. For GBIF and VertNet,

108 automated download was possible; however, for REMIB and UNIBIO, we requested and were

109 provided with data 'dumps,' as some of the data were restricted from full public access (REMIB)

110 or not yet fully available to the public (UNIBIO). The full set of sources contributing data to this

111 analysis is provided in the Appendix.

112 Data reduction and cleaning.-Initial data downloads totaled hundreds of thousands of

113 records from Mexico from each of the data portals, reaching millions from GBIF (although the

114 GBIF numbers are largely from eBird and aVerAves, which come in greatest part from post-1980;

115 Fig. 1, Table 1). We expected considerable redundancy between data sources, in the form of

116 situations in which the same species was collected or recorded at the same place on the same day,

117 so we embarked on a lengthy process of data reduction and cleaning. Without a doubt, some

118 mistakes were made, and some information was lost, but this effort aimed to detect and highlight

119 the major features of Mexican bird DAK, rather than all of the details. That is, we focused on

120 sites that had the most information available, and explicitly excluded information for less-well-

121 known sites.

122 A first step was to concatenate all four datasets into a single, larger dataset, and to reduce

123 the set of fields to the essential three suites of fields mentioned above: species (we retained order,

124 family, genus, and species, to permit identification of the most difficult names), date collected

125 (year, month, and day), and place (latitude and longitude, when available, and state, municipality,

126 and specific locality). We filtered these records to remove all those records from years after 1980.

127 The initial total of 2,598,478 records distilled to 845,658 (a 67.5\% reduction) that both (1) had

128 dates and (2) were not from after 1980. 

species, which included diverse name combinations, and required considerable work to arrive at a consistent suite of names corresponding to the birds of Mexico. We avoided the temptation to attempt to take the taxonomic treatment to a newer authority list (e.g., Gill \& Donsker 2014;

Navarro-Sigüenza \& Peterson 2004; Peterson \& Navarro-Sigüenza 2006) because taxonomic splitting, which has dominated recent years of taxonomic work, would cause considerable confusion of names applied to older records. Hence, we reduced the initial, highly redundant set of names to 1027 names that coincided with the taxonomy of the American Ornithologists' Union (AOU 1998), except that we merged Empidonax traillii and E. alnorum, in light of very frequent confusion in identification (Heller et al. 2016). This step was achieved based on long years of experience with Mexican bird taxonomy, plus occasional consultation of the literature (Monroe \& Sibley 1993; Peters 1931-1987) and online (http://avibase.bsc-eoc.org/) resources.

145 (http://openrefine.org), which permitted many important initial steps of combining similar names, and in Microsoft Access, which permitted development of customized queries for further 147 refinement.

Here, we used a three-step process that aimed to retain a maximum of locality information, yet avoid the massive and prohibitive task of full georeferencing of all records for which no geographic coordinates were available. Hence, (1) we used the 502,935 records that had latitude-

152 longitude data in a first-pass analysis that aimed to identify single sites that were well 153 inventoried, and to identify somewhat broader 'hotspots' of sampling (details provided below). 
154 Next (2), we used locality names associated with the records falling in the hotspots to probe the 155 data lacking georeferences, and thereby rescued >54,000 records. Finally (3), we inspected the 156 remaining data records — those lacking georeferences — to identify additional sites that merited

157 analysis (5 such additional, un-georeferenced sites indeed proved to be relatively well-

158 inventoried, such that this step was important; see below). In this way, the number of localities

159 that needed to be georeferenced was minimized, and yet we managed to include the great bulk of 160 Mexican DAK in our analyses.

161 Step 1: Here, we aimed to develop first analyses of the 502,935 records from the original

162 data set that carried latitude-longitude coordinates, both to identify individual pixels $\left(0.05^{\circ}\right.$

163 resolution) that were well-inventoried, and to identify concentrations ("hotspots") of sampling

164 that may or may not prove to be well-inventoried. We first filtered this data set to retain only the 165 records that were within $0.05^{\circ}(5-6 \mathrm{~km})$ of the administrative outline of Mexico - this step left 166499,794 (99.4\%) records for initial analysis. This initial data set was further reduced to 481,409 167 (95.7\%) that came from 1980 or before.

168 We then created a shapefile with square elements of $0.05^{\circ}$ for Mexico, and eliminated 169 pixels that were $>0.05^{\circ}$ from the administrative boundaries of Mexico. We then used a spatial join 170 to count numbers of records in each polygon; numbers of records per cell ranged from nil to as 171 high as 15,464 (a pixel centered on Chilpancingo, Guerrero). We used optimized hot spot analysis 172 (implemented in ArcGIS, version 10.2) to identify concentrations of sampling effort across the 173 country - we used the Getis-Ord Gi* statistic (Hot Spot Analysis tool), and focused only on 174 hotspots $\left(0.05^{\circ}\right.$ grid squares) significant at the highest (99\%) confidence level. We isolated these 175 well-sampled suites of pixels as a separate shapefile, and then merged pixels in contiguous sets as 176 preliminary hypotheses of broader hotspots of sampling, which we enriched with more records in 177 step 2 (see below). 
179 were well-inventoried, as follows. The 481,409 pre-1980 records remaining after clipping to the

180 country boundaries reduced to 277,249 (57.6\%) unique combinations of species x date x pixel.

181 We calculated $S_{o b s}$ as the number of species that have been recorded from each pixel, $N$ as the

182 total number of unique combinations of species $\mathrm{x}$ date from each pixel (and thus we set a base

183 spatial resolution as that of the $0.05^{\circ}$ grid, such that co-occurrences of species within these pixels

184 are assumed to be sympatric), and $a$ and $b$ as the numbers of species recorded exactly once and

185 exactly twice, respectively, from each pixel. We then used these data to calculate, for each pixel,

186 the Chao2 estimator of expected species richness, with its associated adjustment for small sample

187 sizes (Colwell 1994-present), as

$$
S_{\text {exp }}=S_{o b s}+\left(\frac{N-1}{N}\right)\left(\frac{a(a-1)}{2(b+1)}\right)
$$

188 Completeness was then calculated as $C=S_{o b s} / S_{\text {exp. }}$ To avoid including occasional localities with 189 small sample sizes and artificially 'complete' inventories, we further removed all pixels for which $190 N<200$. We summarized these calculations in a table, which we then imported into ArcGIS and 191 joined to the fishnet shapefile for visualization.

192 Step 2: This step aimed to assess the fairly large portion of the data that lacked 193 georeferences (195,371 records), and 'rescue' relevant data for further enrichment of the hotspot 194 analysis. That is, in Step 1, we used georeferenced occurrence data to identify hotspots of sampling, but many more occurrences were documented in records lacking such data. Hence, 196 here, first, we used the merged hotspot shapefile to associate the original occurrence data (i.e., 197 records with georeferences) to hotspots, and identified key locality names among those 198 occurrence data. (e.g., the Comitán hotspot included localities such as “La Trinitaria,” “El 
199 Triunfo," “Lagunas de Montebello,” “Las Margaritas,” and “Santa Rosa”). Finally, we used those

200 names to probe the non-georeferenced data records (checking, of course, that offset distances

201 were not $>5 \mathrm{~km}$ ), and thereby rescued 54,369 records that were added to the hotspot-based

202 analyses. Inventory statistics and completeness values were then recalculated for each hotspot

203 just as they were calculated in Step 1 for each pixel.

204 Step 3: This final step involved review of the remaining non-georeferenced records, even

205 after the rescue of Step 2. That is, Step 2 focused on non-georeferenced records that corresponded

206 to already-identified pixels and hotspots, and that could be used to enrich the existing

207 (georeferenced) data from those sites. This third step, however, involved a look at the remaining 208 data to see if additional well-known sites could be identified.

We assembled the raw locality descriptors, and tallied numbers of records associated with

210 each; we did some minor cleaning and synonymizing of minor variants on locality descriptors to

211 maximize numbers of records for each locality. Finally, we developed completeness indices (as

212 described above) for each of the non-georeferenced localities that had a raw sample size (i.e.,

213 unique combinations of locality descriptor, year/month/day, and species) of $\geq 200$ records.

214 Because the focus of these exercises is on detecting the few well-inventoried sites, rather than

215 characterizing the overall sampling landscape, no biases are introduced by this rescue step. All

216 localities meeting an arbitrary criterion of completeness, $C \geq 0.8$, were then georeferenced and

217 included among well-known sites.

218 Data availability. All data managed in this study are openly available, or will be shortly,

219 as institutional permissions are finalized, from GBIF (http://www.gbif.org), VertNet

220 (http://www.vertnet.org/), REMIB (http://www.conabio.gob.mx/remib/doctos/remib esp.html),

221 and UNIBIO (http://unibio.unam.mx/). A full synonymy of locality names in relation to the

222 hotspots identified in this paper is available at http://hdl.handle.net/1808/20674. GIS shapefiles 
223 showing the two sets of hotspots identified in this paper are available at

224 http://hdl.handle.net/1808/20673.

\section{Results}

226 Processing data available for birds of Mexico from raw DAK downloads into usable records of 227 species at localities on particular days involved considerable reduction in numbers of records

228 (Table 1). Simply progressing from raw to unique combinations of species $\mathrm{x}$ locality $\mathrm{x}$ geographic coordinates $x$ year x month $x$ day involved a reduction of 20.1-26.2\% in numbers of records (note that this reduction step was done prior to removing records post-1980). Subsequent data cleaning and reduction steps (see Methods, above) reduced redundancy both among data sources (GBIF, VertNet, REMIB, UNIBIO) and among nearby localities, leaving a final number of 481,409 233 records for analysis.

A first analysis focused on 277,249 unique combinations of species $\mathrm{x}$ date collected $\mathrm{x}$ $0.05^{\circ}$ pixel. These records fell in pixels in numbers ranging from nil to 15,464 records (Chilpancingo, Guerrero). Processing records in each pixel into estimates of expected numbers of species and estimated inventory completeness (Table 2; Fig. 2), we found that 24 pixels were complete at the level of $C \geq 0.9$, and a further 71 pixels were complete at the level of $C \geq 0.8$. The well-inventoried sites were well-distributed across the country, from Baja California Sur and

240 Sonora to Quintana Roo and Chiapas (Fig. 2). A further five localities were rescued from among 241 the pool of data lacking geographic coordinates, but that were inventoried completely to the level 242 of $C \geq 0.8$ (Table 3). Seeking 'hotspots' of sampling (i.e., sets of contiguous $0.05^{\circ}$ pixels), we identified an

244 initial large number of such hotspots, again well-distributed across the country. Our inspection of 245 the data lacking geographic coordinates 'rescued' 54,369 records, augmenting the initial data set 246 considerably. Of the initial sampling hotspots, only three made the $C \geq 0.9$ completeness criterion 
247 (Xalapa, Veracruz; El Triunfo, Chiapas; Isla Cozumel, Quintana Roo); another 17 fell at the lower

$248 C \geq 0.8$ criterion (Table 4). These hotspots covered areas ranging from $60.5-4325.8 \mathrm{~km}^{2}$,

249 considerably larger than the $\sim 30 \mathrm{~km}^{2}$ of the $0.05^{\circ}$ pixels. The hotspots, once again, ranged across

250 the country, from southern Sonora to Chiapas and Quintana Roo (Fig. 3).

\section{Discussion}

252 This contribution is an exploration of the utility of the existing digital accessible knowledge

253 (Sousa-Baena, Garcia \& Peterson 2013) for Mexican birds in identifying well-inventoried sites

254 across the country. We chose our 1980 cut-off to coincide roughly with the transition between

255 initial (subtle) climate changes and the present phase of rapid, large-scale climate change

256 worldwide (IPCC 2013). In this way, the sites that we have identified provide baseline points of

257 reference for species composition, for comparison with species composition later, decades into

258 the processes of global climate change (Tingley et al. 2009).

259 One could map the species diversity that has been documented or that we have estimated

260 for $0.05^{\circ}$ grid squares and/or hotspots across the country, to obtain a picture of species diversity

261 countrywide. We have avoided this temptation, however, in view of the highly non-random and

262 scattered distribution of the well-inventoried sites across the country. The sites do not cover all

263 regions of the country at all consistently, so any the results would be incomplete and potentially

264 misleading. That step was, quite simply, not among the objectives of this study.

265 Rather, our aim was to compile a catalog of sites across Mexico that have been

266 inventoried historically in detail, to the point that the inventory is more or less complete. This

267 catalog, in and of itself, is not of great interest scientifically; however, to the extent that new

268 inventories can be developed for comparison with the old ones, the interest in the comparisons

269 grows considerably. Echoing our earlier contribution (Peterson et al. 2015), we are fascinated by 
270 the long-term processes of population biology and biogeography that are leading to turnover of

271 species at sites.

272 We have improved on our earlier contribution (Peterson et al. 2015), however, which had

273 to aggregate occurrence data to coarse resolutions $\left(1^{\circ}\right.$, or $\left.\sim 110 \mathrm{~km}\right)$ until inventories were

274 sufficiently complete. Here, in contrast, we have sought single sites $\left(0.05^{\circ}\right.$ grid squares $)$ that are

275 completely inventoried — this difference has the major advantage of not including as much beta

276 diversity in single-site inventories as did our previous study. Our consideration of hotspots, to

277 some degree, began to coarsen the spatial extent of the sites once again, but offered a somewhat

278 more extensive list of sites that have seen thorough inventories, yet still across extents much

279 smaller than in our previous work.

280 One criticism that can be leveled at this work is that some important data may have been

281 left out of the analysis. That is, the entire concept of digital accessible knowledge is that the data

282 are (1) in digital format, (2) accessible readily via the Internet, and (3) integrated with the

283 remainder of DAK via common portals (i.e., making the transition from individual data points to

284 integrated "knowledge"), as was emphasized in the original publication presenting the idea of

285 DAK (Sousa-Baena, Garcia \& Peterson 2013). [We note that a subsequent publication (Meyer et

286 al. 2015) used “digital accessible information,” we believe unfortunately, as they provided no

287 justification for or even notice of the change of terminology.] In the case of Mexican birds, for

288 example, the Natural History Museum (UK) has very few data in digital format, and none has

289 been made accessible, such that important collections from Mexico, like those assembled by

290 Godman \& Salvin (1879-1915), have not been analyzed in this contribution. That is the blessing

291 and the curse of DAK: data that are digital and shared on global portals are used broadly, whereas

292 data that do not meet the DAK criteria are frequently not used at all.

293 The purpose of this paper is to enable a broad suite of repeat avifaunal survey efforts

294 across Mexico. In effect, with the maps and tables of this paper, we challenge the ornithological 
community interested in Mexican birds to focus attention on these sites (we provide a complete

296 compendium of the well-inventoried sites and hotspots documented in this paper, as well as

297 associated shapefiles, in a dataset made available permanently at

298 http://hdl.handle.net/1808/20673). Not only does work at these sites provide information about

299 the current community composition there, but also about the change in those communities

300 through time.

301 We suggest and advocate that resurvey efforts take the form of two inventories at or near

302 the site: one in as exactly the original site as is possible to determine, and the other in the closest

303 and most comparable site that still retains the vegetation type that was represented at the site at

304 the time of the original inventory efforts; the former reflects effects of local-scale processes (e.g.,

305 habitat destruction, aridification), whereas the latter reflects more global processes (e.g., climate

306 change), and comparisons of the two resurvey inventories will yield a rich understanding of the

307 relative magnitude of effects of the local and global processes in changing avifaunas across the

308 country. Once several such sites have been re-surveyed, a rich picture of the dynamics of

309 Mexican bird distributions will emerge, in much greater detail than the picture presently available

310 (Peterson et al. 2015).

311 We are working to assemble what historical photographs exist for each of these sites, in

312 association with the original inventory efforts, to further enrich comparisons of 'before' and

313 'after.' For instance, the Nelson and Goldman expeditions across Mexico in the late nineteenth

314 and early twentieth centuries produced large quantities of images that are well-documented in

315 two summary volumes (Goldman 1951; Nelson 1921)_two examples are shown in Fig. 4. A

316 major complement to the repeat inventories that are facilitated by the analyses in this study would

317 be repeat photography to allow a clear view of what sorts of landscape change have occurred at

318 key sites (see, e.g., Spond, Grissino-Mayer \& Harley 2014). 
319

320

322

\section{Conclusions}

Valuable insights can be gained from longitudal comparisons to detect and characterize patterns of change in biodiversity, yet such changes have been opaque to study for lack of paired temporal samples at sites or in areas. This study explores a novel approach to enabling such studies: we mine the existing DAK for Mexican birds to detect and document well-inventoried sites, and provide a catalog of those well-known sites for others to use. Developing repeated inventories at a series of sites across Mexico would yield a detailed, controlled set of comparisons that would allow a view of avifaunal dynamics across the country. Adding the dimension of repeated landscape photography to the repeated inventories would greatly facilitate pairing of sites for future inventories at sites for which historical information exists.

\section{Acknowledgements}

We thank the Instituto de Biología and the Comisión Nacional para el Uso y Conocimiento de la Biodiversidad for generously supplying access to data.

\section{References}

AOU. 1998. Check-list of North American Birds, 7th ed. Washington, D.C.: American Ornithologists' Union. Colwell RK. 1994-present. EstimateS. Storrs: University of Connecticut.

Colwell RK, and Coddington JA. 1994. Estimating terrestrial biodiversity through extrapolation. Philosophical Transactions of the Royal Society of London B 335:101-118.

Gill F, and Donsker D. 2014. IOC World Bird List, version 4.3; doi : 10.14344/IOC.ML.4.3.

Godman FD, and Salvin O. 1879-1915. Biologia Centrali-Americana [published in 215 parts by various authors]. London: Taylor and Francis.

Goldman EA. 1951. Biological Investigations in Mexico. Smithsonian Miscellaneous Collections 115:1-476. Grixti JC, and Packer L. 2006. Changes in the bee fauna (Hymenoptera: Apoidea) of an old field site in southern Ontario, revisited after 34 years. Canadian Entomologist 138:147-164.

Heller EL, Kerr KC, Dahlan NF, Dove CJ, and Walters EL. 2016. Overcoming challenges to morphological and molecular identification of Empidonax flycatchers: A case study with a Dusky Flycatcher. Journal of Field Ornithology.

IPCC. 2013. Climate Change 2013: The Physical Science Basis. Cambridge: Cambridge University Press. Lavergne S, Mouquet N, Thuiller W, and Ronce O. 2010. Biodiversity and climate change: integrating evolutionary and ecological responses of species and communities. Annual Review of Ecology, Evolution, and Systematics 41:321-350. 
350

351

352

353

354

355

356

357

358

359

360

361

362

363

364

365

366

367

368

369

370

371

372

373

374

375

376

377

378

379

380

381

382

383

384

385

386

387

388

389

390

391

392

393

394

395

396

Leache AD, Helmer D-S, and Moritz C. 2010. Phenotypic evolution in high-elevation populations of western fence lizards (Sceloporus occidentalis) in the Sierra Nevada Mountains. Biological Journal of the Linnean Society 100:630-641.

Meyer C, Kreft H, Guralnick RP, and Jetz W. 2015. Global priorities for an effective information basis of biodiversity distributions. PeerJ.

Monroe BLJ, and Sibley CG. 1993. A World Check-list of Birds. New Haven: Yale University Press.

Moritz C, Patton JL, Conroy CJ, Parra JL, White GC, and Beissinger SR. 2008. Impact of a century of climate change on small-mammal communities in Yosemite National Park, USA. Science 322:261264. 10.1126/science.1163428

Navarro-Sigüenza AG, and Peterson AT. 2004. An alternative species taxonomy of Mexican birds. Biota Neotropica 4: http://www.biotaneotropica.org.br/v4n2/pt/abstract?article+BN02304022004.

Nelson EW. 1921. Lower California and its Natural Resources. Memorias of the National Academy of Sciences, Washington 16:1-194.

Nilsson SG, Franzén M, and Jönsson E. 2008. Long-term land-use changes and extinction of specialised butterflies. Insect Conservation and Diversity 1:197-207.

Nunes MFC, Galetti M, Marsden S, Pereira RS, and Peterson AT. 2007. Are large-scale distributional shifts of the Blue-winged Macaw (Primolius maracana) related to climate change? Journal of Biogeography 34:816-827.

Olvera-Vital A. 2012. Avifauna del Municipio de Misantla, Veracruz. Tesis de Licenciatura. Mexico: Facultad de Ciencias, Universidad Nacional Autónoma de México.

Peters JL. 1931-1987. Check-list of Birds of the World, vols. 1-16. Cambridge: Harvard University Press.

Peterson AT, and Navarro-Sigüenza AG. 2005. Hundred-year changes in the avifauna of the Valley of Mexico, Distrito Federal, Mexico. Huitzil 7:4-14.

Peterson AT, and Navarro-Sigüenza AG. 2006. Consistency of taxonomic treatments: A response to Remsen (2005). Auk 123:885-887.

Peterson AT, Navarro-Sigüenza AG, Martínez-Meyer E, Cuervo-Robayo AP, Berlanga H, and Soberón J. 2015. Twentieth century turnover of Mexican endemic avifaunas: Landscape change versus climate drivers. Science Advances 1:e1400071.

Peterson AT, and Slade NA. 1998. Extrapolating inventory results into biodiversity estimates and the importance of stopping rules. Diversity and Distributions 4:95-105.

Rubidge EM, Monahan WB, Parra JL, Cameron SE, and Brashares JS. 2011. The role of climate, habitat, and species co-occurrence as drivers of change in small mammal distributions over the past century. Global Change Biology 17:696-708.

Sánchez G. A. 1998. Misantla: Cultura, Tradición y Leyenda. Veracruz: Asociación para el Desarrollo Integral de la Región de Misantla, A.C.

Scholes RJ, and Biggs R. 2005. A biodiversity intactness index. Nature 434:45-49.

Soberón J, and Llorente JE. 1993. The use of species accumulation functions for the prediction of species richness. Conservation Biology 7:480-488.

Sousa-Baena MS, Garcia LC, and Peterson AT. 2013. Completeness of Digital Accessible Knowledge of the plants of Brazil and priorities for survey and inventory. Diversity and Distributions 20:369-381.

Spond MD, Grissino-Mayer HD, and Harley GL. 2014. Comparing dynamics of mixed-conifer woodlands on the Bandera Lava Flow, New Mexico. Southwestern Naturalist 59:235-243.

Tingley MW, and Beissinger SR. 2009. Detecting range shifts from historical species occurrences: New perspectives on old data. Trends in Ecology and Evolution 24:625-633.

Tingley MW, Monahan WB, Beissinger SR, and Moritz C. 2009. Birds track their Grinnellian niche through a century of climate change. Proceedings of the National Academy of Sciences USA 106:19637-19643. 10.1073/pnas.0901562106 
398 Table 1. Summary of initial data downloaded from each of four biodiversity data portals for

399 Mexican vertebrate classes, and the relative redundancy of records in each, at the level of species

$400 \mathrm{x}$ time (year, month, day) $\mathrm{x}$ place (geographic coordinates, textual descriptions). Note that

401 subsequent data cleaning steps changed these initial tallies of redundancy, as they sought

402 synonymies for taxon and place that may not have been visible in this initial step.

\begin{tabular}{lrrrr}
\hline & GBIF & VertNet & REMIB & UNIBIO \\
\hline Raw records & $2,426,732$ & 299,280 & 584,569 & 29,348 \\
Unique records & $1,917,800$ & 226,004 & 431,240 & 23,446 \\
Percent reduction & 21.0 & 24.5 & 26.2 & 20.1 \\
\hline
\end{tabular}


403 Table 2 . Summary of individual $0.05^{\circ}$ grid squares that are well inventoried $(C \geq 0.8)$ across

404 Mexico. Names of grid squares refer to the shapefile dataset summarizing the geographic

405 distribution of these sites.

\begin{tabular}{|c|c|c|c|c|c|c|c|c|c|}
\hline State & Name & Latitude & Longitude & $N$ & $S_{o b s}$ & $a$ & $b$ & $S_{\text {exp }}$ & $C$ \\
\hline \multirow[t]{2}{*}{ Baja California } & Isla Cedros & 28.208 & -115.244 & 213 & 45 & 12 & 10 & 51.0 & 0.88 \\
\hline & Isla San Benito & 28.308 & -115.594 & 398 & 60 & 19 & 11 & 74.2 & 0.81 \\
\hline \multirow[t]{6}{*}{ Baja California Sur } & El Triunfo 2 & 23.808 & -110.094 & 267 & 56 & 15 & 9 & 66.5 & 0.84 \\
\hline & La Paz 2 & 24.158 & -110.244 & 1167 & 137 & 35 & 34 & 154.0 & 0.89 \\
\hline & Laguna San Ignacio 2 & 27.308 & -112.894 & 339 & 55 & 17 & 11 & 66.3 & 0.83 \\
\hline & San Jose de Cabo & 23.058 & -109.694 & 1339 & 174 & 47 & 25 & 215.5 & 0.81 \\
\hline & Sierra de la Laguna & 23.458 & -109.794 & 314 & 56 & 9 & 5 & 62.0 & 0.90 \\
\hline & Sierra de la Laguna 4 & 23.558 & -109.944 & 813 & 55 & 14 & 6 & 68.0 & 0.81 \\
\hline \multirow[t]{6}{*}{ Chiapas } & El Fénix & 16.658 & -93.994 & 258 & 68 & 14 & 12 & 75.0 & 0.91 \\
\hline & Escuintla / Finca La Esperanza & 15.358 & -92.644 & 1362 & 229 & 45 & 31 & 259.9 & 0.88 \\
\hline & Laguna Ocotal & 16.808 & -91.444 & 531 & 125 & 21 & 30 & 131.8 & 0.95 \\
\hline & Pueblo Nuevo & 17.158 & -92.894 & 480 & 133 & 39 & 28 & 158.5 & 0.84 \\
\hline & San Cristóbal de las Casas & 16.658 & -92.594 & 339 & 69 & 17 & 11 & 80.3 & 0.86 \\
\hline & San Cristóbal de las Casas 3 & 16.708 & -92.694 & 342 & 65 & 18 & 11 & 77.7 & 0.84 \\
\hline \multirow[t]{6}{*}{ Chihuahua } & Arroyo del Alamo & 29.458 & -106.794 & 214 & 76 & 21 & 17 & 87.6 & 0.87 \\
\hline & Arroyo el Mesteo & 29.408 & -106.894 & 208 & 76 & 22 & 21 & 86.4 & 0.88 \\
\hline & Colonia Pacheco & 28.658 & -106.194 & 283 & 63 & 17 & 9 & 76.6 & 0.82 \\
\hline & Colonia Pacheco 2 & 30.108 & -108.294 & 945 & 103 & 21 & 9 & 124.0 & 0.83 \\
\hline & Rancho Pinos Altos & 28.258 & -108.294 & 259 & 49 & 8 & 5 & 53.6 & 0.91 \\
\hline & Rio El Gavilan & 30.008 & -108.394 & 325 & 83 & 19 & 15 & 93.7 & 0.89 \\
\hline Ciudad de México & Xochimilco & 19.258 & -99.094 & 229 & 83 & 30 & 21 & 102.7 & 0.81 \\
\hline Coahuila & Sabinas & 27.858 & -101.144 & 625 & 114 & 28 & 17 & 135.0 & 0.84 \\
\hline Colima & Cihuatlan & 19.208 & -104.544 & 354 & 89 & 24 & 15 & 106.2 & 0.84 \\
\hline \multirow[t]{6}{*}{ Durango } & El Salto & 23.758 & -105.544 & 205 & 55 & 12 & 16 & 58.9 & 0.93 \\
\hline & Neveros & 23.758 & -105.744 & 264 & 65 & 16 & 15 & 72.5 & 0.90 \\
\hline & Nievero & 24.008 & -104.744 & 215 & 52 & 12 & 12 & 57.1 & 0.91 \\
\hline & Santa Gertrudis & 23.558 & -104.394 & 254 & 86 & 27 & 17 & 105.4 & 0.82 \\
\hline & Santa Teresa & 22.608 & -104.844 & 264 & 68 & 16 & 10 & 78.9 & 0.86 \\
\hline & Tamazula & 24.958 & -106.944 & 225 & 99 & 37 & 29 & 121.1 & 0.82 \\
\hline Guanajuato & Rancho Enmedio & 21.108 & -101.194 & 401 & 82 & 22 & 14 & 97.4 & 0.84 \\
\hline \multirow[t]{6}{*}{ Guerrero } & Acahuizotla 2 & 17.358 & -99.394 & 476 & 129 & 41 & 26 & 159.3 & 0.81 \\
\hline & Ajuchitlán & 18.158 & -100.494 & 219 & 40 & 9 & 4 & 47.2 & 0.85 \\
\hline & Chilpancingo & 17.558 & -99.494 & 6530 & 270 & 50 & 22 & 323.3 & 0.84 \\
\hline & Cuapongo & 17.508 & -99.644 & 1443 & 169 & 48 & 30 & 205.4 & 0.82 \\
\hline & Omiltemi 2 & 17.558 & -99.644 & 2419 & 206 & 47 & 30 & 240.9 & 0.86 \\
\hline & Teotepec & 17.458 & -100.194 & 254 & 47 & 10 & 6 & 53.4 & 0.88 \\
\hline Jalisco & Atoyac & 20.008 & -103.594 & 316 & 107 & 31 & 24 & 125.5 & 0.85 \\
\hline
\end{tabular}




\begin{tabular}{|c|c|c|c|c|c|c|c|c|c|}
\hline & Atoyac 2 & 20.008 & -103.544 & 223 & 72 & 20 & 15 & 83.8 & 0.86 \\
\hline & Lagos de Moreno 2 & 21.508 & -101.694 & 202 & 70 & 24 & 15 & 87.2 & 0.80 \\
\hline & Tapalpa & 19.958 & -103.744 & 288 & 102 & 34 & 22 & 126.3 & 0.81 \\
\hline \multirow[t]{7}{*}{ Michoacán } & Apatzingan & 19.158 & -102.444 & 244 & 68 & 18 & 12 & 79.7 & 0.85 \\
\hline & Pátzcuaro & 19.458 & -101.594 & 361 & 111 & 35 & 23 & 135.7 & 0.82 \\
\hline & Rancho El Bonete & 18.958 & -101.894 & 297 & 95 & 30 & 20 & 115.6 & 0.82 \\
\hline & Tzitzio & 19.608 & -100.944 & 285 & 78 & 19 & 13 & 90.2 & 0.87 \\
\hline & Tzitzio 2 & 19.658 & -100.894 & 299 & 97 & 32 & 22 & 118.5 & 0.82 \\
\hline & Uruapan & 19.408 & -101.994 & 391 & 94 & 26 & 14 & 115.6 & 0.81 \\
\hline & Zacapu & 19.808 & -101.794 & 475 & 126 & 34 & 30 & 144.1 & 0.87 \\
\hline Morelos & Cuernavaca & 18.908 & -99.244 & 541 & 159 & 50 & 32 & 196.1 & 0.81 \\
\hline \multirow[t]{3}{*}{ México } & East of Zitácuaro & 19.408 & -100.194 & 250 & 77 & 22 & 14 & 92.3 & 0.83 \\
\hline & Puerto Lengua de Vaca & 19.258 & -99.894 & 224 & 63 & 14 & 14 & 69.0 & 0.91 \\
\hline & Temascaltepec & 19.058 & -100.044 & 632 & 128 & 29 & 21 & 146.4 & 0.87 \\
\hline \multirow[t]{6}{*}{ Nayarit } & Islas Tres Marías & 21.458 & -106.444 & 394 & 64 & 15 & 15 & 70.5 & 0.91 \\
\hline & Islas Tres Marías 3 & 21.458 & -106.394 & 475 & 68 & 20 & 12 & 82.6 & 0.82 \\
\hline & San Blas 3 & 21.558 & -105.294 & 701 & 235 & 75 & 50 & 289.3 & 0.81 \\
\hline & Sauta & 21.708 & -105.144 & 370 & 107 & 34 & 20 & 133.6 & 0.80 \\
\hline & Tepic & 21.258 & -104.644 & 207 & 69 & 18 & 20 & 76.3 & 0.90 \\
\hline & Tepic 2 & 21.508 & -104.894 & 1126 & 178 & 43 & 22 & 217.2 & 0.82 \\
\hline \multirow[t]{6}{*}{ Oахаса } & Cerro San Felipe & 17.158 & -96.694 & 236 & 66 & 16 & 10 & 76.9 & 0.86 \\
\hline & Chivela & 16.708 & -94.994 & 251 & 73 & 20 & 16 & 84.1 & 0.87 \\
\hline & Palomares & 17.108 & -95.044 & 782 & 213 & 67 & 44 & 262.1 & 0.81 \\
\hline & Rancho San Carlos & 17.208 & -94.944 & 340 & 127 & 42 & 28 & 156.6 & 0.81 \\
\hline & Rio Molino & 16.058 & -96.444 & 374 & 84 & 17 & 16 & 92.0 & 0.91 \\
\hline & Totontepec & 17.258 & -96.044 & 533 & 107 & 15 & 30 & 110.4 & 0.97 \\
\hline \multirow[t]{3}{*}{ Quintana Roo } & Felipe Carrillo Puerto & 19.558 & -88.044 & 212 & 86 & 26 & 31 & 96.1 & 0.89 \\
\hline & Felipe Carrillo Puerto 2 & 19.608 & -88.044 & 342 & 131 & 45 & 37 & 157.0 & 0.83 \\
\hline & Isla Cozumel 4 & 20.508 & -86.944 & 650 & 154 & 17 & 49 & 156.7 & 0.98 \\
\hline \multirow[t]{2}{*}{ Sinaloa } & Babizos & 25.758 & -107.444 & 472 & 81 & 20 & 10 & 98.2 & 0.82 \\
\hline & Rancho Liebre & 23.558 & -105.844 & 601 & 126 & 26 & 21 & 140.7 & 0.90 \\
\hline \multirow[t]{8}{*}{ Sonora } & Babizos 2 & 27.008 & -108.394 & 539 & 106 & 29 & 18 & 127.3 & 0.83 \\
\hline & Chinobampo & 26.958 & -109.294 & 215 & 74 & 22 & 22 & 84.0 & 0.88 \\
\hline & Hacienda de San Rafael & 27.108 & -108.694 & 220 & 61 & 18 & 14 & 71.2 & 0.86 \\
\hline & Huasa & 28.608 & -109.794 & 221 & 66 & 21 & 12 & 82.1 & 0.80 \\
\hline & La Chumata & 29.908 & -110.594 & 241 & 68 & 15 & 17 & 73.8 & 0.92 \\
\hline & Oposura & 29.808 & -109.694 & 494 & 124 & 27 & 24 & 138.0 & 0.90 \\
\hline & Rancho Guirocoba 2 & 26.958 & -108.694 & 879 & 168 & 39 & 27 & 194.4 & 0.86 \\
\hline & Tecoripa & 28.608 & -109.944 & 242 & 75 & 21 & 18 & 86.0 & 0.87 \\
\hline \multirow[t]{5}{*}{ Tamaulipas } & Above Ciudad Victoria & 23.708 & -99.244 & 202 & 75 & 2 & 49 & 75.0 & 1.00 \\
\hline & Ciudad Victoria & 23.708 & -99.144 & 370 & 177 & 52 & 33 & 215.9 & 0.82 \\
\hline & Gomez Farías 3 & 23.058 & -99.094 & 354 & 123 & 44 & 32 & 151.6 & 0.81 \\
\hline & Matamoros & 25.858 & -97.494 & 628 & 207 & 60 & 42 & 248.1 & 0.83 \\
\hline & Tampico & 22.258 & -97.844 & 1038 & 211 & 47 & 41 & 236.7 & 0.89 \\
\hline Veracruz & Balzapote 4 & 18.608 & -95.044 & 3491 & 286 & 56 & 43 & 321.0 & 0.89 \\
\hline
\end{tabular}




\begin{tabular}{|c|c|c|c|c|c|c|c|c|c|}
\hline & Cerro Guzman & 19.208 & -96.394 & 542 & 141 & 43 & 29 & 171.0 & 0.82 \\
\hline & Coatepec & 19.458 & -96.944 & 377 & 122 & 16 & 49 & 124.4 & 0.98 \\
\hline & Coyame & 18.408 & -94.994 & 338 & 129 & 30 & 41 & 139.3 & 0.93 \\
\hline & Huatusco & 19.158 & -96.944 & 282 & 95 & 26 & 30 & 105.4 & 0.90 \\
\hline & Lago de Catemaco & 18.408 & -95.144 & 205 & 79 & 28 & 21 & 96.1 & 0.82 \\
\hline & Misantla & 19.908 & -96.844 & 307 & 108 & 3 & 62 & 108.0 & 1.00 \\
\hline & Perote & 19.558 & -97.244 & 263 & 88 & 14 & 44 & 90.0 & 0.98 \\
\hline & Presidio 2 & 18.658 & -96.744 & 1000 & 219 & 54 & 36 & 257.6 & 0.85 \\
\hline & Rancho Caracol 3 & 18.458 & -96.644 & 358 & 127 & 41 & 26 & 157.3 & 0.81 \\
\hline & Xalapa & 19.558 & -96.944 & 887 & 192 & 34 & 54 & 202.2 & 0.95 \\
\hline \multirow[t]{3}{*}{ Yucatán } & Chichén-Itzá & 20.658 & -88.594 & 1727 & 193 & 26 & 23 & 206.5 & 0.93 \\
\hline & Mérida & 20.958 & -89.644 & 242 & 118 & 38 & 25 & 144.9 & 0.81 \\
\hline & Xocompich & 20.758 & -88.544 & 270 & 115 & 44 & 40 & 138.0 & 0.83 \\
\hline
\end{tabular}


407 Table 3. Summary of additional sites that were 'rescued' from among digital data lacking

408 geographic coordinates, but that were detected based on unique locality descriptors.

\begin{tabular}{|c|c|c|c|c|c|c|c|c|c|}
\hline State & Locality name & Latitude & Longitude & $N$ & $S_{o b s}$ & $a$ & $b$ & $S_{\text {exp }}$ & $C$ \\
\hline Nuevo León & Monterrey & 25.687 & -100.316 & 418 & 145 & 52 & 38 & 178.9 & 0.81 \\
\hline Tabasco & 1 mi E Teapa & 17.563 & -92.948 & 361 & 158 & 57 & 41 & 195.9 & 0.81 \\
\hline San Luis Potosí & [Ciudad] Valles & 21.997 & -99.011 & 227 & 93 & 34 & 26 & 113.7 & 0.82 \\
\hline Chiapas & $26 \mathrm{~km} \mathrm{~N}$ by road Ocozocuautla & 16.995 & -93.379 & 400 & 145 & 55 & 40 & 181.1 & 0.80 \\
\hline Oaxaca & 1 mi SW Valle Nacional & 17.757 & -96.320 & 485 & 169 & 54 & 46 & 199.4 & 0.85 \\
\hline
\end{tabular}


409 Table 4. Hotspots of sampling that are relatively completely inventoried (i.e., $C \geq 0.8$ ). Hotspot

410 names correspond to the shapefile dataset summarizing the geographic distribution of these sites.

411

\begin{tabular}{|c|c|c|c|c|c|c|c|}
\hline State & Hotspot & $N$ & $S_{o b s}$ & $a$ & $b$ & $S_{\text {exp }}$ & $C$ \\
\hline \multirow[t]{4}{*}{ Chiapas } & Arriaga Tonalá & 2162 & 337 & 88 & 53 & 407.86 & 0.83 \\
\hline & Comitán & 3821 & 422 & 79 & 62 & 470.9 & 0.89 \\
\hline & El Triunfo & 4884 & 396 & 41 & 34 & 419.4 & 0.95 \\
\hline & Tuxtla Gutiérrez & 4058 & 463 & 93 & 54 & 540.8 & 0.86 \\
\hline \multirow{2}{*}{$\begin{array}{l}\text { Ciudad de México } \\
\text { Guerrero }\end{array}$} & Valle de México & 6818 & 349 & 71 & 28 & 434.7 & 0.80 \\
\hline & Chilpancingo / Omiltemi & 15230 & 380 & 51 & 24 & 431.0 & 0.88 \\
\hline \multirow{2}{*}{ Michoacán } & Patzcuaro / Morelia / Lagos de Michoacán & 2144 & 269 & 60 & 26 & 334.5 & 0.80 \\
\hline & Tancítaro / Uruapan & 1396 & 253 & 50 & 28 & 295.2 & 0.86 \\
\hline Nayarit & Tepic / San Blas & 5079 & 405 & 66 & 34 & 466.3 & 0.87 \\
\hline \multirow[t]{3}{*}{ Oaxaca } & Matías Romero to north & 3994 & 404 & 84 & 42 & 485.0 & 0.83 \\
\hline & Miahuatlán / Mixtepec & 1054 & 205 & 54 & 34 & 245.9 & 0.83 \\
\hline & Tapanatepec / Zanatepec / Cerro El Baúl & 4752 & 355 & 63 & 28 & 422.3 & 0.84 \\
\hline Quintana Roo & Isla Cozumel & 2159 & 216 & 39 & 46 & 231.8 & 0.93 \\
\hline \multirow{2}{*}{ Sinaloa } & Durango Hwy / Espinazo del Diablo & 3857 & 293 & 57 & 24 & 356.8 & 0.82 \\
\hline & Rosario & 1912 & 247 & 55 & 35 & 288.2 & 0.86 \\
\hline \multirow{4}{*}{$\begin{array}{l}\text { Sonora } \\
\text { Veracruz }\end{array}$} & Álamos & 3403 & 273 & 42 & 23 & 308.9 & 0.88 \\
\hline & Los Tuxtlas & 10499 & 457 & 78 & 41 & 528.5 & 0.87 \\
\hline & Orizaba / Córdoba & 2741 & 402 & 94 & 52 & 484.4 & 0.83 \\
\hline & Xalapa & 2135 & 303 & 54 & 49 & 331.6 & 0.91 \\
\hline Yucatán & Chichén-Itzá & 2612 & 220 & 37 & 20 & 251.7 & 0.87 \\
\hline
\end{tabular}


412 Fig. 1. Digital accessible knowledge of bird distributions (481,409 unique combinations of 413 species x place $x$ time) across Mexico prior to 1980, drawn from GBIF, VertNet, REMIB, and 414 UNIBIO (records are not coded by source owing to frequent overlaps among sources in serving 415 copies of the same record).

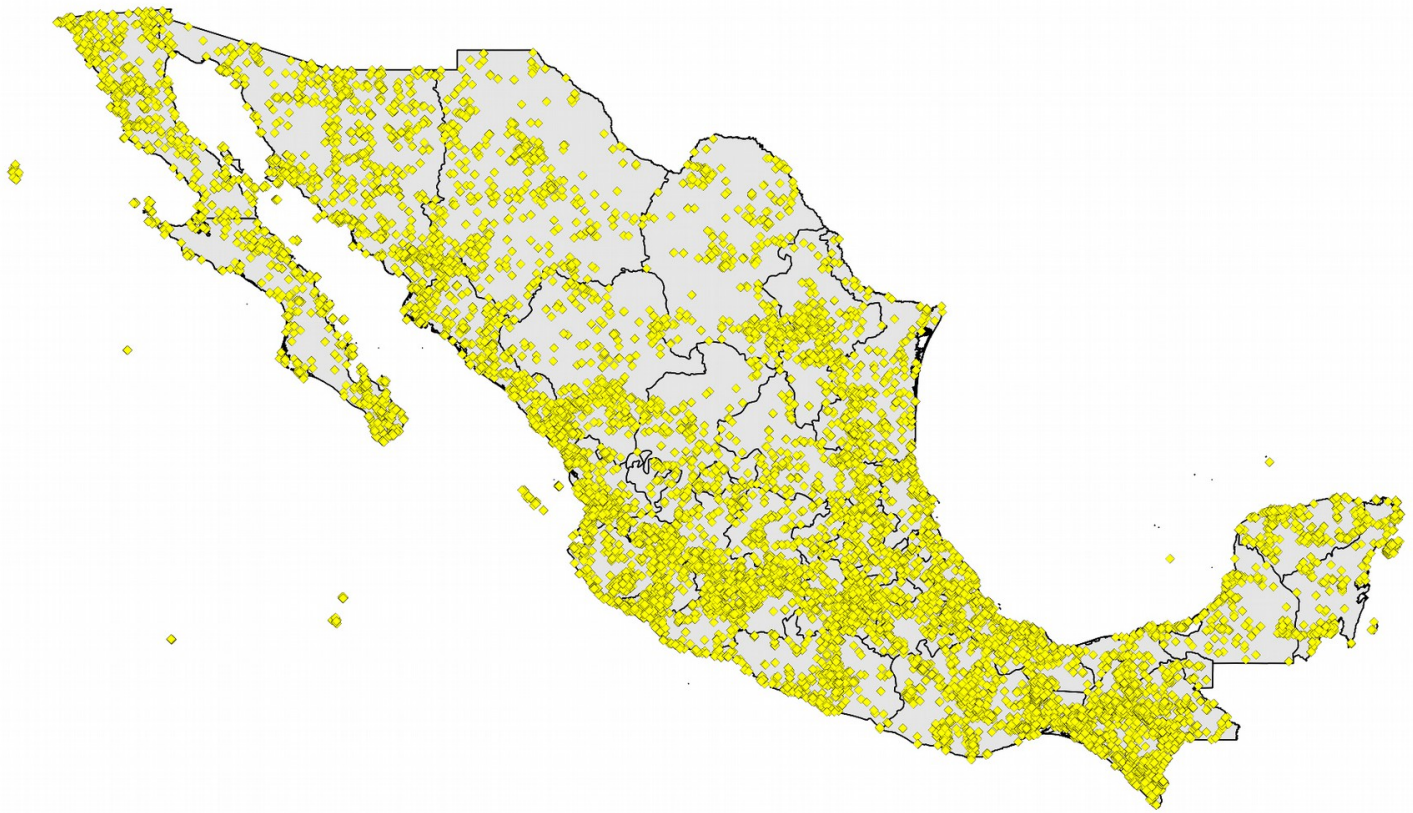


416 Fig. 2. Distribution of single $0.05^{\circ}$ grid squares for which $>200$ records were available and

417 completeness $(C)$ was $0.8 \leq C<0.9$ (pink) or $C>0.9$ (brown). Sites detected in Step 3 (i.e., single 418 sites that are relatively complete, but that were not georeferenced prior to this study) are shown in 419 blue (all had $0.8<C<0.9$ ).

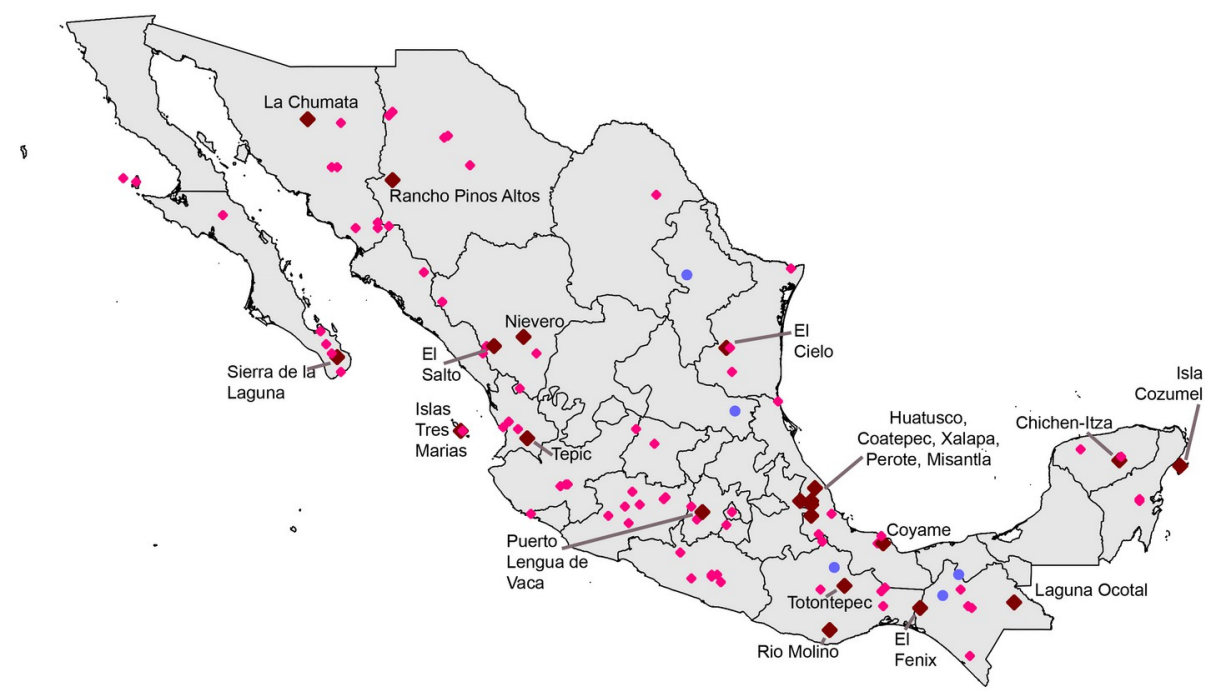


420 Fig. 3. Summary of "hotspots" of sampling of Mexican avifaunas based on the Getis-Ord Gi* 421 statistic. Gray areas have $0.8 \leq C<0.9$; red areas have $C>0.9$.

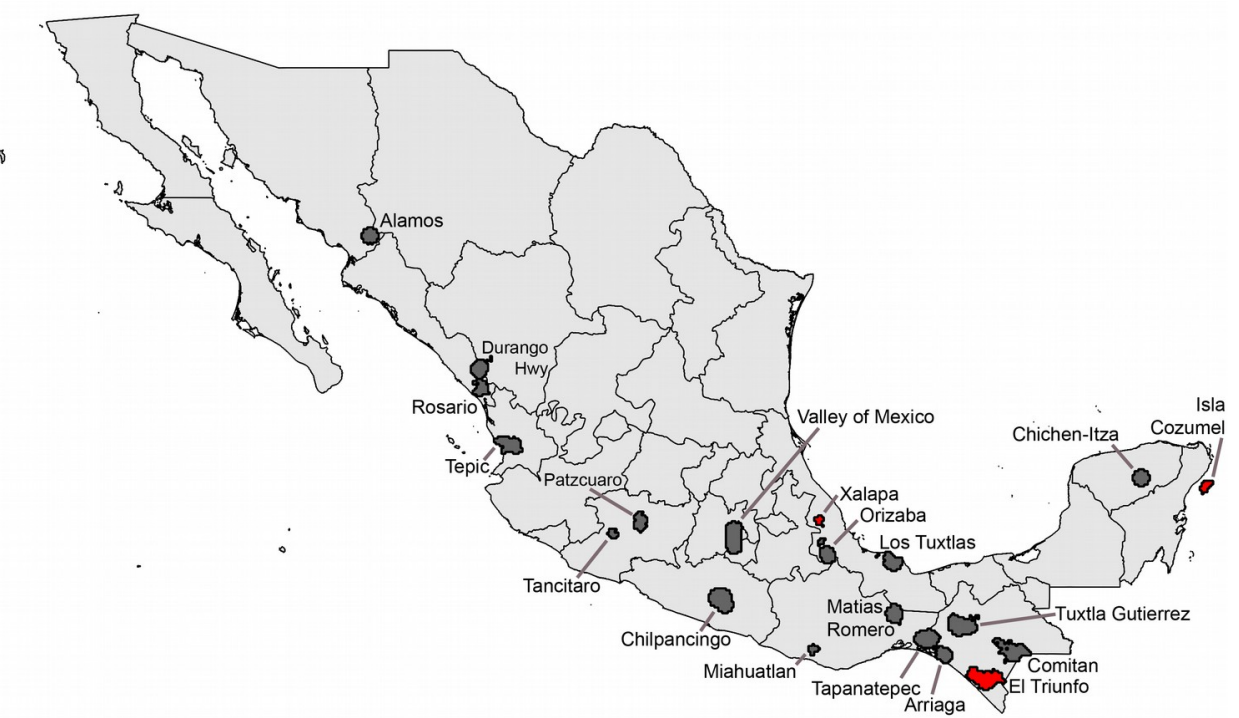


422 Fig. 4. Photos of landscapes of two of the hotspots identified in this study from the Nelson-

423 Goldman expeditions across Mexico in the late nineteenth and early twentieth centuries: above

424 Xalapa, Veracruz (SIA2014-03203), Mt. Tancítaro, Michoacán (SIA2011-1908). Photos

425 reproduced with permission of the Smithsonian Institution, Washington, D.C.

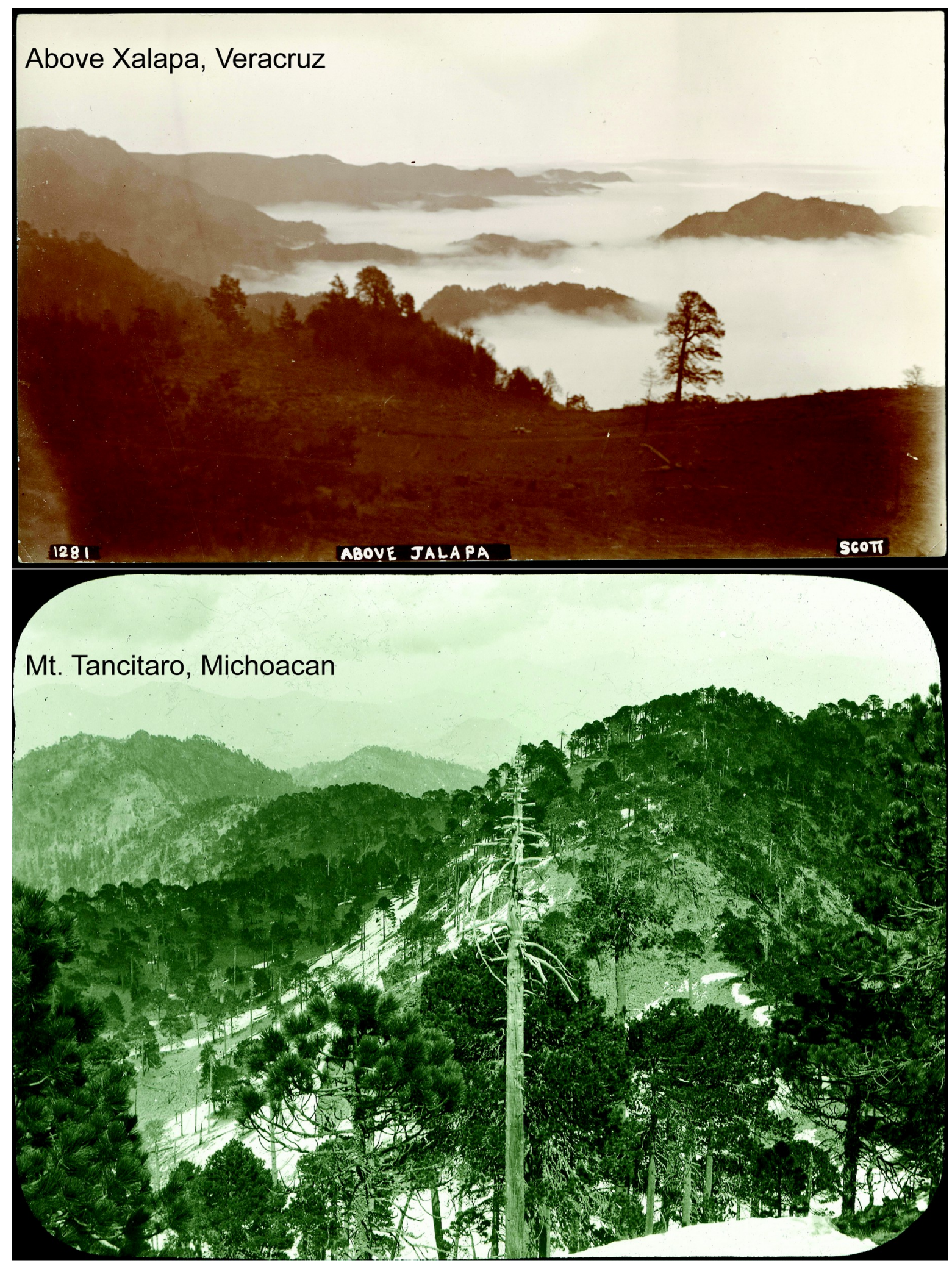




\section{Appendix}

Sciences of Philadelphia; American Museum of Natural History; Angelo State University;

Australian National Wildlife Collection; Bell Museum of Natural History; Biologiezentrum Linz;

Bird Studies Canada; Borror Laboratory of Bioacoustics; Burke Museum, University of

Washington; California Academy of Sciences; California State University, Chico; Canadian

Museum of Nature; Carnegie Museum of Natural History; Chicago Academy of Sciences;

CIIDIR-Oaxaca; Comisión Nacional para el Uso y Conocimiento de la Biodiversidad; Cornell

Laboratory of Ornithology; Delaware Museum of Natural History; Denver Museum of Nature \&

Science; ECOSUR Chetumal; ECOSUR San Cristóbal; Emporia State University; Estación

Natural History; Fort Hays State University; HawkCount; Humboldt State University; Illinois

State University; iNaturalist; INIFAP; Instituto de Biología, Universidad Nacional Autónoma de

México; Instituto de Ecología, A.C., Xalapa; Instituto de Historia Natural de Chiapas; Instituto

Humboldt, Colombia; Louisiana State University; Lund Museum; Michigan State University;

Moore Laboratory of Zoology; Musée de la Vallée, Barcelonette, France; Musée George Sand et

442 de la Vallée Noire; Museo de las Aves de México; Museo de Zoología "Alfonso L. Herrera,"

443 Facultad de Ciencias, Universidad Nacional Autónoma de México; Museo Nacional de Ciencias

444 Naturales; Museu Paraense Emilio Goeldi; Museum für Naturkunde, Berlin; Museum Heineanum

445 Halberstadt; Museum National d'Histoire Naturelle; Museum of Comparative Zoology, Harvard

446 University; Museum of Evolution, Uppsala; Museum of Nature and Human Activities, Hyogo,

447 Japan; Museum of Southwestern Biology; Museum of Vertebrate Zoology; Museum Victoria,

448 Australia; Natural History Museum (Bird Group, Tring); Natural History Museum of Los

449 Angeles County; Naturalis, Amsterdam; Neotropical Ornithological Foundation; New York State

450 Museum; North Carolina Museum of Natural Sciences; Ocean Biodiversity Information System; 
451 Ohio State University; Orcutt Trust Collection; Perot Museum of Nature and Science; Polish

452 Academy of Sciences; Provincial Museum of Alberta; Queensland Museum; Royal Belgian

453 Institute of Natural Sciences; Royal Ontario Museum; San Diego Natural History Museum; Santa

454 Barbara Museum of Natural History; Senckenberg Museum; Slater Museum of Natural History;

455 South Australian Museum; Staatliche Naturhistorische Sammlungen Dresden, Museum für

456 Tierkunde; Staatliches Museum für Naturkunde, Stuttgart; Tall Timbers Research Station and

457 Land Conservancy; Texas A\&M University; Tulane University; U.S. National Museum of

458 Natural History; Uberseemuseum, Bremen; Universidad Autónoma de Baja California;

459 Universidad Autónoma de Baja California Sur; Universidad Autónoma de Campeche;

460 Universidad Autónoma de Nuevo León; Universidad Autónoma de San Luis Potosí; Universidad

461 Autónoma de Tamaulipas; Universidad Autónoma del Estado de Hidalgo; Universidad Autónoma

462 del Estado de México; Universidad Autónoma del Estado de Morelos; Universidad de Ciencias y

463 Artes de Chiapas; Universidad de Guanajuato; Universidad de Navarra; Universidad Juárez

464 Autónoma de Tabasco; Universidad Juárez del Estado de Durango; Universidad Michoacana de

465 San Nicolás de Hidalgo; University Museum of Zoology, Cambridge; University of Alabama;

466 University of Alaska Museum; University of Alberta; University of Arizona; University of British

467 Columbia; University of California, Davis; University of California, Los Angeles; University of

468 Colorado; University of Iowa; University of Kansas; University of Michigan Museum of

469 Zoology; University of Nebraska State Museum; University of Oklahoma; University of Oslo;

470 University of Texas El Paso; University of Wyoming; Utah Museum of Natural History;

471 Washington State University; Western Foundation of Vertebrate Zoology; Western New Mexico

472 University; Yale Peabody Museum; Yamashina Institute of Ornithology; Zoologische

473 Staatssammlung München; and Zoologischen Sammlung der Universitat Rostock. 